Euskal ikerketen aldizkaria | Revue d'études basques |

Revista de estudios vascos | Basque studies review

Numéro Spécial 1 | 1999

Les lettres basques au temps d'Axular (1600-1650)

\title{
Axular euskal hitzen ordenaren historian
}

Axular et l'étude diachronique de l'ordre des mots dans la phrase basque

\section{Victor Hidalgo Eizagirre}

\section{OpenEdition \\ Journals}

Édition électronique

URL : http://journals.openedition.org/lapurdum/1605

DOI : 10.4000/lapurdum.1605

ISSN : 1965-0655

Éditeur

IKER

Édition imprimée

Date de publication : 1 octobre 1999

Pagination : 143-170

ISBN : 2-84127-157-9

ISSN : $1273-3830$

Référence électronique

Victor Hidalgo Eizagirre, «Axular euskal hitzen ordenaren historian », Lapurdum [Linean], Numéro

Spécial 1 | 1999, Sarean emana----an 01 juin 2010, kontsultatu 31 janvier 2020. URL : http://

journals.openedition.org/lapurdum/1605; DOI : 10.4000/lapurdum.1605 


\section{Victor HIDALGO}

\section{AXULAR EUSKAL HITZEN ORDENAREN HISTORIAN ${ }^{1}$}

\section{Villasante / Mitxelena, 1952-3}

1951 n izendatzen dute Aita Villasante euskaltzain, aurreko urtean zendua zen Julio Urkijoren ordez. 1952rako prestatzen du bere sarrera hitzaldia Euskaltzaindian, eta izenburu esanguratsua ematen dio: "Literatur-euskara. Laphurrtarr klassikoaren gain eratua". Halako izenburu bete baten ondotik espero zitekeen bezala, bertan lapurtera klasikoaren berreskurapena proposatzen da maila jasoko euskararen erabilpenetarako, gerora ere, esateko, Krutwigek eta Jakintza Baitha-k urte luzez defendatu eta erabiliko dituzten bideen antzekoetatik. Hala ere, Villasanterentzat, Axular zen eredu nagusia (gerora urte askoan bere lanetan setati erakutsiko duen bezala), beste lapurtar klasikoak ere gutxietsi gabe, eta oso bereziki Etxeberri Sarakoa. Halaz guztiz, eredu hauei, Villasante berak ere, ez die garaian erabat imitagarri iritziko, sintaxi / joskera kontuetan. Ez, hauek egiten duten partikula anaforikoen edo hainbat juntagailuren erabilera erdal zalean (generikoki zeinismoa deituko den hartan); eta ez, guri orain gehiago dagokigun kontuan, haien esaldi barreneko hitzen ordenamenduaren atalean. Eta hala proposatuko du orduan Villasantek, ausart, bere esaldietako aditzak ezin gehiagoan atzeratzen dituen bitartean, berak bertan defendatu nahi duen kanonari jarraiki $(1952,286)$ :

Agian, eredutzat hautatu diren idazleen liburuak, berriz argitaratzekoan, syntaxis aldetik zuzenduak atheratzeko asmoa elitzateke okherra. Hunelako liburuetan eskuak ibentzea arriskuz betheriko egitekoan sartzea dela ba dakit. Baina euskara zuzen eta kanonikoaren ithurri eta maisu izaiteko egiten diren edizinoetan horrenbertze haizu litekela dirudi.

Egin beharreko zuzenketen eredua, izango dira, jakina, Altubek 1920-30 inguruan eginiko joskera istudi zorrotzak-Villasanteren hitzetan-.

Beharrik, Mitxelenak erantzungo dio publikoki Villasanteren proposamen horri hurrengo urtean, eta aipatu Villasanteren hitz berorien iruzkina eginez galdetu eta erantzungo du $(1953,460)$ :

\section{Zer esan? Itz bat dator biotz-barrendik: Absit!}

Utikan! Mitxelena 1952an aukeratzen dute euskaltzain aurreko urtean hildako Azkueren ordezko. Eta bere sarrera hitzaldi ofiziala 1961era arte egingo ez duen arren, 1953an egiten du Euskaltzaindian bertan Arnaut Oihenart-i buruzko hitz jarduna. Honen amaieran, ordea, gaiarekin zerikusi handirik gabe, baina barrenari eutsi ezinda edo, eta Villasanteren sarrera hitzaldiko "Axulartar" haiei egingo die erantzuna joskera kontu horien inguruan. Eta hala egingo ditu Mitxelenak, aipatu Absit!-Utikan!-aren ondotik, nik ezagutu dizkiodan hitz gogorrenak, baina 
eta era berean justuenak ere bai seguru asko, Altuberen lege horien kontra. Eta hala dio $(1953,460)$ :

Labur esateko, Altube jaunak finkatutako legeak, euskerak gorde bear lituzkeanak izango dira agian, baiña ez euskerak gorde edo gordetzen dituenak.

Mitxelenak argi iradokiko die halako Axulartarrei $(1953,460)$ : tela.

Ba-dirudi, beraz, gure literatura klasikoari segi nai diotenek erabat segi bear lioke-

Hau da, joskera kontuetan ere bai.

Gerora, kontu interesgarri, eta jakin beharreko ugari konta liteke Villasante / Mitxelena, jada aurrerantzean tandem anti-altubetar bihurtuko den honen inguruan, ${ }^{2}$ hurrengo 35 urteetan joskeraren harian. Ikusi besterik ez, Villasantek urte horietan guztietan joskera kontuei eskainiko dizkien liburu eta artikulu pilak, denak ondo kontuan hargarriak, eta beti Mitxelenaren nolabaiteko itzalpean burutuak. Gure gaurko gaia, ordea, Axular da, eta harengana itzuliko gara.

\section{Lekuona, 1954}

Manuel Lekuonak prestatuko du 1954rako Gero-ren 4. argitalpena, Euskaltzaindiak berak bultzatua, eta Lekuonak bere hitzaurrean ez dio muzin egingo aurreko urte bietako Villasante-Mitxelena eztabaidari. Manuel Lekuona bera, Azkueren ikasle da hitz ordenaren kontuetan bere Gasteizko apaizgaitegiko urteetatik, eta jada 1918an ematen du argitara berak ere, h.d. Altubek berak baino urtebete lehenago, "galdegaiaren legea", lehenago Azkuek berak 1894an, Luis Elizaldek 1911n, edota jada modu zabalagoan Paulo Zamarripak 1918an egin modu beretsuan. Lekuona, beraz, Altube bera baino lehenago izango da altubetar, bere Gasteizko ikaskide izan zen J.M. Barandiaran izango den modu beretsuan. Lekuonak, nolanahi, bere argitalpenean ez du ukituko, ez du aldatuko, Axularren sintaxirik. Nahiz, liburuari eginiko Aitzin-solas-ean, errepasoa bai egingo dion Axularren joskera "erdal zaleari" garaiko aireen bahetik, eta AKATS izenburupean izendatu eta tratatuko ditu Villasantek Axularri atxikitzen zizkion ezaugarri ez-imitagarri haiek berak: anaforiko eta juntagailuen erabilera latinizantea, nola haren hitzen ordenamendua, finean, Axularrek ez duelako aditza behar beste atzeratzen esaldian garaiko gusturako.

Lekuonak, nolanahi, Axularren estiloa oro har goraipatu ondoren, honen meritutzat jasoko du estiloaren laburra, eta hain zuzen, balizko laburtasun honi atxiki nahiko dio guztiek Axularren idazkerari aitortzen dioten argitasuna (1954, XXI):

Argi oni, leuntasun oni, berdintasun oni -ori bai- asko laguntzen dio laburtasunak.

Esakun laburra. Estilo laburra. Eta, izan ere, Axular eztegu bat-ere parrafo-zale.

Lekuonak, ordea, nahita edo nahigabe nahastu egiten ditu halako usteetan, batetik bere preskripzio propioak liratekeenak, eta bestetik, Axularren ezaugarriak, zerikusi handirik ez dutenak halako idazkera motz nahikoekin. Zeren, Axularrez zer edo zer esaterik ez badago, horixe da, gure ustez, hain zuzen: labur zalea denik. Zeren, Axular, guztien gainetik, oparoa da; esaldi luzea idazten du inondik ere. Eta hala sartuko gara Axularren lehen ezaugarri batzuekin. 
Guk 1994an hitzen ordenaren inguruan eginiko estatistiketan (Hidalgo, 1994a), konpara genezake Axular, batetik, beste ipar zein hegoaldeko zenbait idazlerekin (J.A. Mogel; J.B. Agirre; Duvoisin; eta J. Etxepare); eta bestetik, baita ere, batez ere ahozko hizkera kontutan hartzen duen corpus zabalago batekin. ${ }^{3}$ Eta hala esan genezake, nola, gure corpus orokor honetan esaldi nagusi luzeak (h.d., 5 edo konplementu gehiagokoak, gure orduko azterketa eskeman), batez beste, guztien $\% 51,0 \mathrm{a}$ diren. Axularrenak, berriz, \%68,5a. Eta aztertu bost idazle klasikoena, batez beste, \%58,2a (Mogelek, \%49,7; Agirrek, \%68,4; Duvoisinek $\% 40,6$; eta Etxeparek, \%66,0), Axular delarik guztietan oparoena, Agirre eta Etxeparerekin batera.

Esaldi nagusi luzeen proportzioak (5 edo konplementu gehiagokoak):

\begin{tabular}{|l|l|}
\hline & $\%$ \\
\hline Axular & $\mathbf{6 8 , 5}$ \\
\hline Corpusa (batez beste) & 51,0 \\
\hline Idazleak (batez beste) & 58,2 \\
\hline J.A. Mogel & 49,7 \\
\hline J.B. Agirre & 68,4 \\
\hline J. Duvoisin & 40,6 \\
\hline J. Etxepare & 66,0 \\
\hline
\end{tabular}

1994an beste irizpide bat ere erabili genuen testuen trinkotasuna juzkatzeko: esaldi nagusi eta mendekoen arteko proportzioak. Mendeko esaldi hauek hiru sailetan banatzen genituelarik: 1. Aditz jokatu bidezko mendeko esaldiak; 2. Aditz jokatugabe bidezkoak; eta 3. Erlatiboak. Axularrek erakusten ditu, era berean, mendeko esaldien proportzio altuenak, Etxeparerekin batera: ehun esaldi nagusiko 242,9 mendeko (\%242,9). Etxeparek \%246,4. Corpuseko batez bestekoa, ez da zifra horien erdira ere iristen: \%115,9. Idazle klasikoen batez bestekoa, berriz, \%178,1 (Mogel, \%174,4; Agirre, \%145,7; Duvoisin, \%118,7). Erlatiboen erabilerari begira ere, Axular oso nabarmena gertatzen da beste guztien aldean. Axularrek 60 erlatibo erakusten ditu ehun esaldi nagusiko $(\% 60,0)$. Corpuseko batez bestekoa \%24,6koa da, eta idazle klasikoen batez bestekoa, \%37,6koa (Mogelek, \%33,9; Agirrek, \%39,6; Duvoisinek, \%22,0; Etxeparek, \%37,4).

Esaldi nagusi eta mendekoen arteko proportzioak:

\begin{tabular}{|l|c|}
\hline & $\%$ \\
\hline Axular & $\mathbf{2 4 2 , 9}$ \\
\hline Corpusa (batez beste) & 115,9 \\
\hline Idazleak (batez beste) & 178,1 \\
\hline J.A. Mogel & 174,4 \\
\hline J.B. Agirre & 145,7 \\
\hline J. Duvoisin & 118,7 \\
\hline J. Etxepare & 246,4 \\
\hline
\end{tabular}

Esaldi nagusi eta erlatiboen arteko proportzioak:

\begin{tabular}{|l|c|}
\hline & $\%$ \\
\hline Axular & $\mathbf{6 0 , 0}$ \\
\hline Corpusa (batez beste) & 24,6 \\
\hline Idazleak (batez beste) & 37,6 \\
\hline J.A. Mogel & 33,9 \\
\hline J.B. Agirre & 39,6 \\
\hline J. Duvoisin & 22,0 \\
\hline J. Etxepare & 37,4 \\
\hline
\end{tabular}


Beraz, gaur eguneko moda ere baden arren, ez dirudi berez derrigorrezko denik labur idaztea argi idazteko. Ez baitio Axularri inork argitasunik ukatu, nahiz luze, eta sintaktikoki korapilotsu, idatzi. Beste zerbaiten baitan da argitasuna. Nolanahi, adierazgarria da jakitea, nola, gure corpusean badiren gaur egungo ahozko zenbait testigantza, Axularrena bera bezain hizkera aberatsa darabiltenak. Baita ere aberatsagoak, zenbait klasikoren idatzian bederen (hala nola, esateko, corpus nagusi horretaz kanpo aztertu dugun Mendibururen itzulpenetakoa: $\% 73,4$ esaldi nagusi 5 edo konplementu gehiagokoak; \%263,8 mendeko esaldi ehun nagusiko; \%94,4 erlatibo ehun nagusiko). Gaur eguneko prosa estandarreko datuak, ordea, ez dira iristen Axularren mailara (\%63,5 esaldi nagusi 5 edo konplementu gehiagokoak; \%153,5 mendeko esaldi ehun nagusiko; \%35,2 erlatibo ehun nagusiko).

\section{Euskal Esnalea, 1909}

1909ko urtean Patrizio Antonio Orkaiztegi Tolosako artzapez Santa Kruz zaleak sustatuko duen Euskal Esnalea aldizkaria hasiko da argitaratzen Geroko gero-ren bertsio gipuzkeratu bat Intxausperen 1864koari jarraiki. Kapitulu gutxi batzuk baino ez dira argitaratuko, baina hauetan ez da jada errespetatuko Axularren joskerarik. Eta halaxe gaztigatzen du Orkaiztegik irakurlea aurkezpen beretik $(1909,115)$ :

Apaiz bat, Ateaga-r J.A. jauna, izango da gure elera Axular-en lan ederra itzuliko duana, itz -joskera egiñalean obetubaz.

Orkaiztegik argitaratua du jada ordurako, 1906an, bere Observaciones para hablar y escribir tolerablemente en nuestro idioma euskaro liburua, aurrerantzean, Azkuek jada lehenago ondo piztutako zeinismoaren kontrako bandera-ikur bihurtuko dena (ik. Azkue, 1891). Aurretik, 1903an, Orkaiztegi sarri da jarduna hitzen joskeraz Azkueren Ibaizabal aldizkarian. Axularri eginiko zuzenketek, berriro, aipatzen gatozen bi alorrak ukituko dituzte: batetik, zeharo desagertuko da bertatik zeinismo kutsuko partikula oro; bestetik, aditzak atzeratuko dira esaldian.

\section{Añibarro, Lardizabal, Kanpion}

Nolanahi, eta aipatutakoak aipatuta, hainbat harritzeko gertatuko bada ere, ehun urte lehenago, Axularrek, hain justu, zeharo bestelako fama du gure hegoaldean. Hain zuzen, aditz atzera zalearena. Hala dio, esateko, Añibarrok, 1820 ingurukoak izan litezkeen hitzetan, bere Gramatikako sarreran (1800a, 14):

... De paso advierto que assi Axular, como el P. Cardaveraz ponen el verbo al último de la oración, a no venir con relativo, y será bien que se haga assi, pues sale mas natural. No tuve este methodo presente en dos libritos que dí a luz EscuLibrua, y Lorategui espirituala. Esta misma falta me dijo que cometió el inmortal Don Juan Antonio de Moguel, ...

Eta ohar honen inguruan badira aipatzeko gauzak. Ezen, batetik, ohar hau idazten duenerako, Añibarrok itzulia du jadaneko Axular bizkaierara (berak aitortzen du hala bertan), eta nahiko bitxia da, nola Añibarrok, besterik gabe nahasten dituen bertan Axular eta Kardaberazen izenak, zuhur jokatuz, soilik azken honi erants dakiokeen ezaugarri baten inguruan. Bi autoreak beharbada 
dira alderagarriak, esateko, beren esaldien luzeratan; baina gehiegitxo dirudi besterik gabe hitz egitea Axularren aditz posposizioaz, Mitxelenaren Axulartar haiek ongi konturatu bezala.

Garrantzia du, ordea, konturatzeak, nola, jada XVIII. mendetik, garaiko airean dabilen kontu bat den euskal aditzaren balizko posposizioarena. Añibarrok Mogel aipatzen du falta beraren egile eta aitorle, nahiz honek, hain zuzen, Kardaberazen 1762 ko bizkaierazko dotrina argitaratzen duen 1783an, eta hain juxtu, zuzendua, aurreratuaz esaldian, Kardaberazek bertan erabat artifizialki atzeratutako aditz haiek berak. Badakigu Kardaberazek 1760a baino lehentxeago aldarrikatzen duela euskal aditz posposizioaren ezaugarri hori, azkenean Larramendiri iritsiko zaion eskutitz batean. Beharbada, Larramendik berak zion jada aireratua halako ezaugarri bat Kardaberazi, biak Loiolako etxean eginiko urte luzeetan, eta ez da azken honen asmaketa hutsa. Bartolome Olaetxea bizkaitarra ere, dudarik gabe da uste horren jabe, bere Dotrina Cristianea-ren bigarren argitalpen aditz atzera zalea prestatzen duenerako, 1763 (1. arg.) eta 1775 bitartean (2. arg.). Gerrikok ere halako susmo baten pean idatziko ditu bere Platikak 1805erako. Eta hala ere, iparraldeko gramatika batean ageriko da, lehen aldiz inprimaturik aipatua, euskal aditz posposizioaren balizko ezaugarria. Hala egingo du J.B. Arxuk bere Uskara eta Frantzes Gramatika-n, 1853an (beharbada, 1852ko argitalpenean ere bai); eta errepikatuko du 1868ko Bi mihiren gramatika-n (1853, 47, nondik jasotzen dugun aipua; 1868, 43-4):

Ez ahantz beraz Franzes hitzkunzan, Pronom eta Verbe deitzen diren hitzac yarten direla ordenariozki beste hitzen aitzinean; Uskaraz aldiz yarten dira beste hitzen ondotic, nola: Berrogoi-ta-sei dira: Ils sont quarante-six. Zazpi alhaba ditu: Il a sept filles. Etche bat nuen: J'avais une maison.

Hegoaldean, balizko aditz posposizioaren lehen aipamen inprimatua hiruzpalau urte beranduago egingo du Lardizabalek 1856an argitaraturiko gramatikan $D e$ la sintaxis ò construcción del Vascuence izeneko Bigarren Parte osoaren amaierako, kapitulu ondo labur batean $(1856,81)$ :

CAPITULO X / Colocacion de las partes de la oracion. / ... / 1. En esta operacion han sido varios los escritores vascongados, sin que se hayan sugetado a un método uniforme, como que la indole del idioma presta esta libertad: sin embargo, para que la oracion salga airosa y elegante, sera muy conveniente, que el verbo se coloque al fin de la oracion, siempre que no viniere con relativo, pues en este caso, se ha de colocar segun este lo exija. Este método de fijar el verbo al fin de la oracion solos Ajular, llamado Ciceron vascongado, en su Gueroco guero, y el P. Cardaveraz en sus varias obras practicaron constantemente; asi es que sus escritos, y cualquiera otro confeccionado en esta forma, se hacen muy dociles a la memoria. El agente puede colocarse en primer lugar, el paciente en segundo, y el adverbio antes del verbo: v.g. Jaungoicoac guizona munduaren asieran eguin zuen, Dios crió al hombre al principio del mundo. Pero advierto, que cuanto digo en este capitulo relativo a la colocacion no es esencial é indispensable para una buena sintasis.

Kurios asko, Lardizabalen hitzak, Axular aipatuz, ez dira Añibarrorenen kopia hutsa baino. Ez dakigu nondik egina. Lardizabalen joskera libertatearen aipamenak, berriz, iparraldeko halako tradizio baten oihartzun izan litezke, Martin Harrietek, bere 1742ko gramatikan, euskararen ordenamendu libertatearen lehen aldarrikapena egiten duenetik frantsesaren aldean. Gerora, finean, errepikatu baino egingo ez dutena Léclusek 1826an, Darrigolek 1827an, Xahok 1836an, Intxauspek 1856an eta 1858an, C.A.F. Mahn-ek eta Francisque-Michel-ek 1857an, Charenceyko Konteak 1862an, Dartayet-ek 1867 eta 1876an, Gèze-k 
1873an, Luchairek 1879an, eta azkenik, Ithurrik 1894an. Hegoaldean, ordenamendu libertate horren oihartzunak iritsiko dira Kanpionenganaino ere Darrigol, Lardizabal eta Intxausperen eskutik. Eta are Azkue berarengana ere inoizka, itsasoko haizeak eman bezala (ik. Azkue, 1896; 1928; 1949).

Hurrengo urteetan, Gregorio Arrue itzultzaile giputza izango da aditz atzera zaletasunaren aitalehena. Ikusi besterik ez, honek bi Mogelei (Juan Jose eta Juan Antoniori) egindako gipuzkeratzeak besteak beste. Azkenik, Kanpionek jasoko du berriro, 1884rako gramatika erraldoian, euskal aditz posposizioaren balizko ezaugarria, Añibarro eta Lardizabalen oihartzun, bertan Axularren izena agerian aipatuko ez bada ere. Hala esango du $(1884,782)$ :

Los buenos escritores y hablistas rematan la frase, por lo común, con el verbo principal de ella.

Hegoaldean, Kanpionez geroztik gertatuak hitzen ordenaren eremuan, Azkue eta Altuberen eskutik etorriko dira, gaurko estandarraren eredu bihurtu arte, eta ez ditugu orain hemen berriro haizatuko (ik. Hidalgo 1991; 1993; 1996).

$* * * * * * * * * * * * * * * * * * * * *$

Zer gertatzen da, ordea, Axularrekin? Zer dugu Axular azkenik? Aditz atzera zalea, Añibarrok eta Lardizabalek dioten legean? Ala zabar axolagabe erromantzatu bat baino ez, bere hitzen joskeran, XX. mendeko hegoaldeko tradiziorik integristenak dioen ildoan? Agian denetik pixkaren bat? Ikusiko dugu.

\section{Axular eta SAO / SOA ordena estatistikak}

1969an argitaratu zituen De Rijk irakasleak lehen estatistikak euskarazko hitzen ordenamenduaren inguruan, kontutan hartuaz esaldiko hiru elementu nagusien ordena erlatiboa (Aditza / Subjektua / Objektua - A / S / O), eta Greenberg irakasle estatu-batuarrak munduko 30 hizkuntzen azterketan (euskara barne) erabilitako irizpideen ildotik.

De Rijkek aztertuko ditu, batetik, hegoaldean, XX. mende honen bigarren erdian, Nemesio Etxaniz azkoitiarrak, dudarik gabe, garaiko estilo AzkueAltubetarrean idatzitako zenbait itzulpen (III. lagina) eta ere sortzezko testu (II. lagina). Bestetik, baita ere, J.M. Barandiaranek, mendearen lehen laurdenaren inguruan, "bildu" eta argitaratutako zenbait kontakizun folkloriko (I. lagina), eta zeinetako gehienek diruditen Barandiaranek berak idatziak. Fidelak, seguru asko, mamian; baina ez hainbeste forman; eta are gutxiago, erakusten duten hitzen ordenamenduan. Honek, beste nonbait erakutsi dugun bezala (ik. Hidalgo 1995), gehiago dirudi propio Barandiaranena, Ataungo hiztunena baino. Barandiaranek "zuzen", "zuzentasunez" idatzia, berak ere seguru asko, Lekuonarekin batera, Gasteizko apaizgaitegian Azkueri ikasitako eredu "zuzen" haien ildotik, honek Euskalerriaren Yakintza-n bertan aitortzen duenaren itxuran. De Rijkek erabilitako corpusak ez zirudien, beraz, aproposegia, hain zuzen, hitzen ordena aztertzeko, eta guk beste corpus zabalago eta fidagarriago baten aztertzeari ekin genion (ik. Hidalgo 1995). Hemen datuak, De Rijkenak, eta gureak: ${ }^{4}$ 
SOA / SAO: De Rijken emaitzak:

\begin{tabular}{|l|c|c|c|c|}
\hline & I & II & III & Denera \\
\hline SOA (SOV) & $\mathbf{6 6 , 0}$ & $\mathbf{4 4 , 0}$ & $\mathbf{6 1 , 0}$ & $\mathbf{5 7 , 0}$ \\
\hline SAO (SVO) & 23,0 & 37,0 & 31,0 & 30,0 \\
\hline OAS (OVS) & 5,0 & 9,0 & 5,0 & 6,0 \\
\hline OSA (OSV) & 2,5 & 7,0 & 1,5 & 4,0 \\
\hline ASO (VSO) & 3,0 & 2,0 & 1,5 & 2,5 \\
\hline AOS (VOS) & 0,5 & 1,0 & 0,0 & 0,5 \\
\hline
\end{tabular}

SAO / SOA: Gure datuak:

\begin{tabular}{|c|c|c|c|c|c|c|}
\hline Autorea eta esaldi kopurua & SAO(SVO) & SOA(SOV) & OAS(OVS) & ASO(VSO) & OSA(OSV) & AOS(VOS) \\
\hline Axular (204) & 48,0 & 25,5 & 12,2 & 9,8 & 2,9 & 1,5 \\
\hline Tartas (244) & 44,3 & 35,7 & 10,7 & 3,7 & 4,9 & 0,8 \\
\hline Mogel (132) & 69,7 & 3,8 & 7,6 & 11,4 & 2,3 & 5,3 \\
\hline J.B. Agirre (200) & 55,5 & 8,5 & 15,5 & 16,5 & 0,0 & 4,0 \\
\hline Duvoisin (253) & 59,3 & 36,8 & 1,2 & 0,4 & 2,0 & 0,4 \\
\hline Patxiko Txerren $^{4}(87)$ & 63,2 & 11,5 & 20,7 & 2,3 & 0,0 & 2,3 \\
\hline Webster (124) & 68,5 & 14,5 & 4,0 & 2,4 & 7,3 & 3,2 \\
\hline Cerquand (284) & 63,7 & 27,8 & 3,9 & 1,4 & 3,2 & 0,0 \\
\hline Urruzuno (132) & 42,4 & 20,4 & 17,4 & 13,6 & 3,8 & 2,3 \\
\hline Laburditar Ipuinak $^{5}(31)$ & 38,7 & 32,3 & 6,4 & 9,7 & 0,0 & 12,9 \\
\hline Zeber io $^{6}(104)$ & 37,5 & 27,9 & 10,6 & 8,6 & 11,5 & 3,8 \\
\hline Refranes y sentencias $^{7}(50)$ & 56,0 & 28,0 & 6,0 & 2,0 & 8,0 & 0,0 \\
\hline Micoleta (14) & 57,1 & 14,3 & 0,0 & 21,4 & 0,0 & 7,1 \\
\hline Kapanaga (45) & 75,6 & 11,1 & 2,2 & 8,9 & 0,0 & 2,2 \\
\hline Viva Jesus (5) & 40,0 & 0,0 & 0,0 & 40,0 & 20,0 & 0,0 \\
\hline Domingo Egia (11) & 27,3 & 18,2 & 36,4 & 9,1 & 9,1 & 0,0 \\
\hline J. Zumarraga (5) & 60,0 & 0,0 & 20,0 & 20,0 & 0,0 & 0,0 \\
\hline Bertso Bizkaitarrak (6) & 50,0 & 16,7 & 0,0 & 16,7 & 16,7 & 0.0 \\
\hline DENERA: $(100 \%)$ & 55,3 & 23,4 & 9,0 & 6,7 & 3,5 & 2.1 \\
\hline Denera: Kopuruak (1.931) & $(1.068)$ & (451) & (174) & (130) & $(68)$ & (40) \\
\hline
\end{tabular}




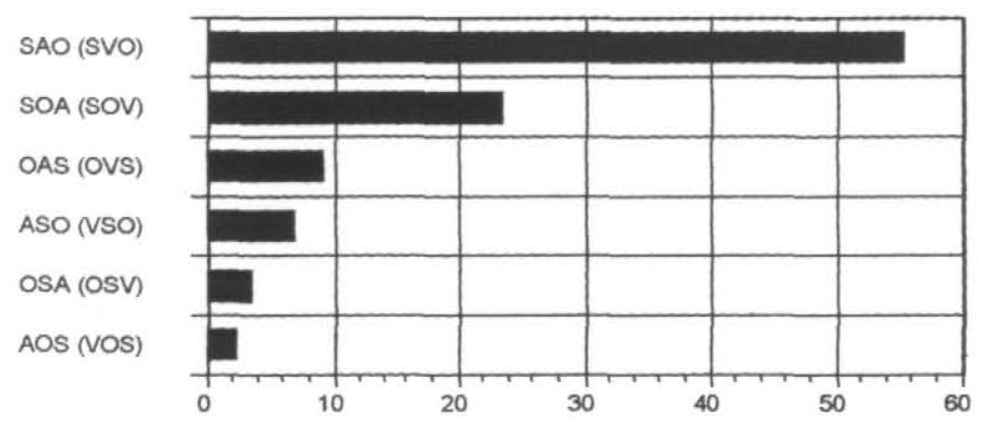

De Rijken emaitzek, estatistikoki ere, nagusiki SOA ordenako hizkuntza bezala azaltzen dute euskara. Nolanahi, bere II. laginean ia parekatzen dira SAO eta SOA multzoak. Kurioski, II. lagin hau da Etxanizek zuzenean euskaraz sortutako antzerkietakoa.

Gure datuek, bestalde, inolako zalantzarik gabe ematen dute euskara SAO ordena nagusiko hizkuntza bezala, grafikoan erraz antzeman litekeen bezala.

Hala ere, badira aipatzea merezi lezaketen puntuak. Ezen, bitxiki, Axular eta Tartasenak dira testu orekatuenetakoak SAO / SOA ordenen artean. Batez bestekoa baino nahikoa orekatuagoak. Tartasen kasuan, beharbada, susmoa dugu, datu desberdinak emango ote lituzkeen bere bigarren liburuak (Arima penitentaren occupatione devotac), baina ez dugu azterketa zehatzik egin ahal izan. Duvoisinen datuek ere oso proportzio altua ematen dute SOA esaldiena, nahiz SAOena ere biziki garaia den Axular edo Tartasen aldean. Eta horrek guztiak, aurrerago ikusiko dugun beste zenbait emaitzekin batera, beharbada bultza gaitzake pentsatzera, hegoalde purista batean uste izan denaren kontrara, hain zuzen, gure iparraldeko idazle klasikoak izan direla hainbat aditz atzera zaleagoak, hegoaldeko idazleak baino. Aurrerago helduko diogu berriro gaiari.

Gure datuetan, ageri dira beste autore edo corpus nahikoa orekatu batzuk ere (Mayi Ariztiaren Laburditar ipuinak, Urruzunoren Ipuinak, edo Zeberioko aho testigantzek), ordea, hirurek garamatzakete pentsatzera beren idazmoldean, modu batera edo bestera, eragin Azkue-Altubetarrak egon ote litezkeen, kasuan kasu zehatzago aztertu beharko liratekeen eraginak.

Berriro iparraldeari dagokionean, berriz, oso esanguratsuak gertatzen dira Webster eta Cerquand-en ipuin bildumetako datuak, biziki SAO zaleak, guk hauekin eginen ez genukeelarik aurrekoekin bezainbeste zalantza transkribapen fideltasunen inguruan, nahiz egin, egin litezkeen, eta egia esan, egin diren.

\section{Axularren aditz nagusiaren guneaz esaldian}

Datu objektiboak dira hauek ere: Aditza esaldi hasieran, tartean edota amaieran ematen duten esaldi nagusien proportzioak. Datu guztiak gure 1994ko lan estatistikotik daude atereak (Hidalgo, 1994a). Axularrenak honen liburuko XXXI-XXXIV kapituluetakoak (denera 175 esaldi nagusi aditz jokatu bidezkoak). Emaitzak segidakoak: ${ }^{9}$ 
Aditzaren gunea esaldi nagusietan:

\begin{tabular}{|l|c|c|c|}
\hline & $\begin{array}{c}\text { Aditza } \\
\text { hasieran }\end{array}$ & $\begin{array}{c}\text { Aditza } \\
\text { tartean }\end{array}$ & $\begin{array}{c}\text { Aditza } \\
\text { amaieran }\end{array}$ \\
\hline Axular & $\mathbf{6 , 9}$ & $\mathbf{5 3 , 7}$ & $\mathbf{3 9 , 4}$ \\
\hline Corpusa (batez beste) & 14,3 & 57,6 & 28,1 \\
\hline Idazleak (batez beste) & 18,1 & 63,4 & 18,6 \\
\hline J.A. Mogel & 32,8 & 56,7 & 10,6 \\
\hline J.B. Agirre & 27,2 & 69,1 & 3,8 \\
\hline J. Duvoisin & 11,2 & 58,5 & 30,3 \\
\hline J. Etxepare & 10,1 & 77,7 & 12,3 \\
\hline Webster & 37,8 & 39,7 & 22,5 \\
\hline Cerquand & 19,2 & 59,1 & 21,7 \\
\hline Euskalkiz euskalki & 13,7 & 49,9 & 36,4 \\
\hline Sara & 22,6 & 46,8 & 30,6 \\
\hline Zuberoa & 10,7 & 55,4 & 33,9 \\
\hline Baigorri & 28,8 & 51,5 & 19,7 \\
\hline Heleta & 23,3 & 43,3 & 33,3 \\
\hline Gaur egun & $\mathbf{1 , 4}$ & $\mathbf{5 9 , 4}$ & $\mathbf{3 9 , 2}$ \\
\hline
\end{tabular}
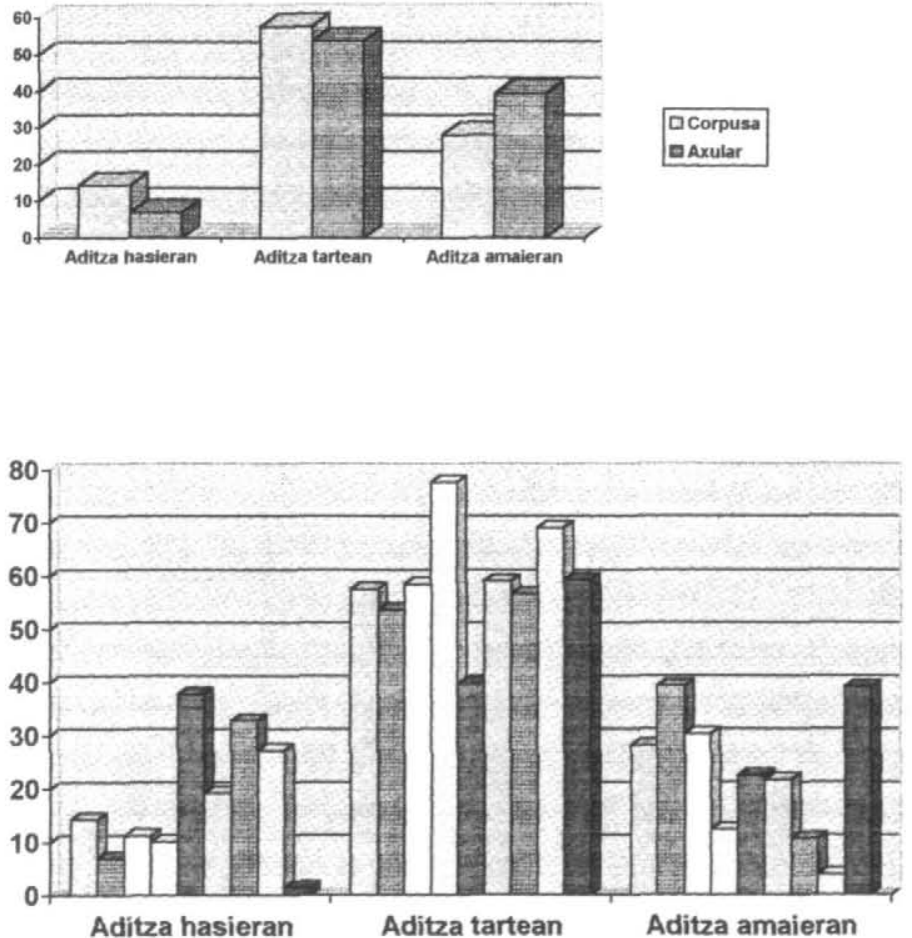
Beraz, nolerebait, bada egia, Axularrek nahikoa maiz ematen duela aditza esaldi amaieran (gaur eguneko prosa estandarrean bezain beste), eta aldiz, nahikoa gutxi, beste zenbaiten aldean bederen, esaldi hasieran bertan (nahiz, hala ere, 5 bider gehiago, gaur eguneko prosa estandarrean baino). Duvoisinen aditz atzeratzeak ere aipagarriak dira beste idazleen aldean. Etxepareren tarteko aditzen kopuru handiak bezalaxe. Berriro ote gaude iparraldeko berezitasunen aurrean?

Datu esanguratsuagoak izango dira, horregatik, aditza tartean erakusten duten esaldi horietatik ekarriak.

\section{Axularren esaldi barreneko aditzak}

Aditza tartean erakusten duten esaldietan, berriz, bi egoera gerta litezke. Batetik, aditz hau joan liteke esaldiaren atzealdean, eta aldiz hala, esaldiko gailur predikatiboa, informazio nagusia, aditz honen aurrean emana, nolerebait AzkueAltuberen legeek agintzen duten moduan. Edota, bestela, alderantziz joan liteke aditza esaldi aurrealdean emana, eta honen gailur predikatiboa, esaldiko pisu informatibo nagusia, aditz honen ondoretik, Azkue-Altuberen legeez bestela. Hau juzkatzea zer edo zer subjektiboxeagoa izan liteke aurreko ataleko kokapen datu objektiboak baieztatzea baino. Eta batzuetan gertatzen da ezin ongi determina litekeela esaldiaren gailur predikatiboa aditzaren aurrean edota atzean ematen den; tarteka bi guneetan ere ematen ahal delako nolerebait. Gertatzen da ere inoiz, aditzak berak jasatea esaldiko gailur predikatiboaren zama. Hau, ordea, praktikan ez da hainbestetan gertatzen. Gure corpusean, hala, sailkatu ezin izandako esaldiak, batez beste, guztien \%10,2 izan dira (\%13,8 Axularrengan). Aldiz, esaldien $\% 89,8$ bat (Axularren \%86,2a) aztertu ahal izan dugu, beren pisu informatiboa aditzaren aurretik, edo ondotik, ematen dutenaren arabera. Emaitzak ezin esanguratsuagoak dira:

Galdegaiaren kokagunea aditza tartean erakusten duten esaldi nagusietan:

\begin{tabular}{|l|c|c|c|}
\hline & $\begin{array}{c}\text { Gald. ad. } \\
\text { Ondotik }\end{array}$ & $\begin{array}{c}\text { Gald. ad. } \\
\text { Aurretik }\end{array}$ & Bestela \\
\hline Axular & $\mathbf{8 1 , 9}$ & $\mathbf{4 , 3}$ & $\mathbf{1 3 , 8}$ \\
\hline Corpusa (batez beste) & 79,0 & 10,8 & 10,2 \\
\hline Idazleak (batez beste) & 73,7 & 12,9 & 13,4 \\
\hline J.A. Mogel & 83,3 & 5,9 & 10,8 \\
\hline J.B. Agirre & 84,7 & 3,8 & 11,5 \\
\hline J. Duvoisin & 68,1 & 19,9 & 12,1 \\
\hline J. Etxepare & 52,5 & 28,8 & 18,7 \\
\hline Webster & 86,6 & 8,7 & 4,7 \\
\hline Cerquand & 70,2 & 17,0 & 12,8 \\
\hline Euskalkiz euskalki & 72,5 & 13,0 & 14,5 \\
\hline Sara & 69,0 & 20,7 & 10,3 \\
\hline Zuberoa & 77,4 & 9,7 & 12,9 \\
\hline Baigorri & 94,1 & 5,9 & 0,0 \\
\hline Heleta & 69,2 & 19,2 & 11,5 \\
\hline Gaur egun & $\mathbf{2 0 , 1}$ & $\mathbf{5 1 , 2}$ & $\mathbf{2 8 , 7}$ \\
\hline
\end{tabular}



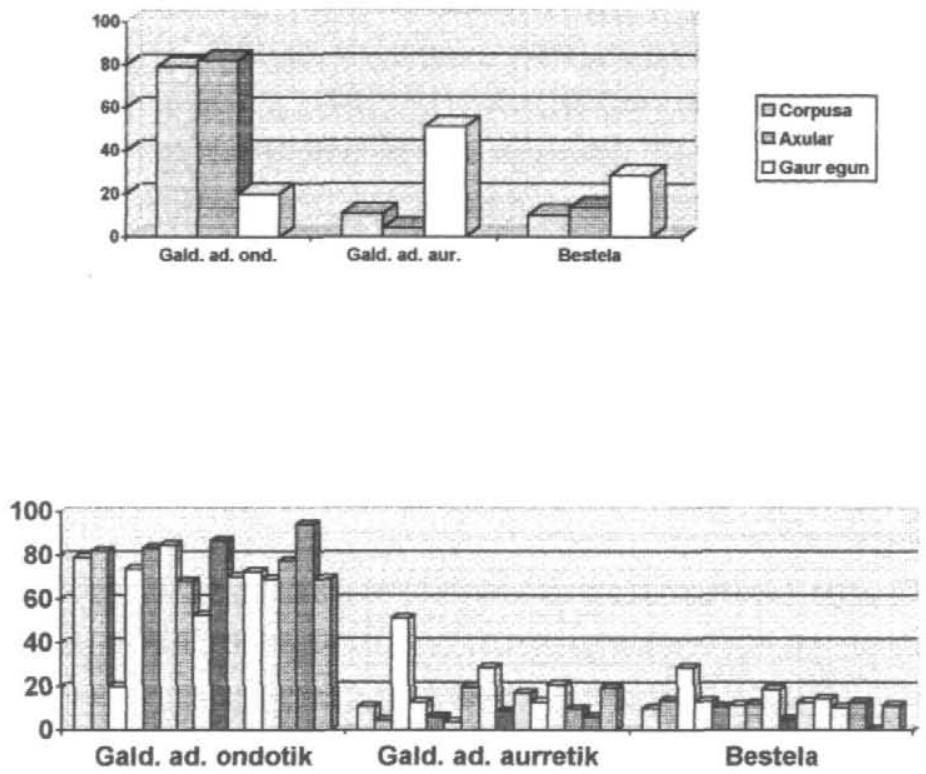

\begin{tabular}{|c|c|c|c|c|}
\hline 口Corpusa & EAxular & $\square$ Gaur egun & Didazleak & EJ.A. Mogel \\
\hline 口J.B. Agirre & 口J. Duvoisin & J. Etxepare & - Webster & DCerquand \\
\hline 口Euskalkiz euskalki & 口Sara & 믐 Zuberoa & घBaigorri & घHeleta \\
\hline
\end{tabular}

Zer esan nahi du honek? Azkue-Altuberen legea, galdegaia esaldiko aditzaren aurretik emateko, ez dela salbuespenez baino betetzen, aditza tartean daramaten esaldietan. Eta inon baino gutxiago Axularren testuan, nondik, noski, Axulartar haien mesfidantzak. Are gehiago, gure datuen arabera orokortu liteke, eta esan, delako legea, ez dela, ez inon, eta ez inolako euskaratan betetzen, salbu gaur egun, eta apropos, Azkue-Altuberen legeak bete nahian, idazten den estandar hartan. Eta soilik hipotesi bezala izango bada ere, pentsatu beharko dugu, gainera, euskaraz, delako Azkue-Altuberen legerik, ez dela inoiz ere bete, dauzkagun dokumentu zaharren guztiek ere, legea inondik betetzen ez duten heinean.

Berriro aipa litezke, nolanahi, iparraldeko Duvoisin eta Etxepareren kasuak. Jasotako lagin guztien artean Etxeparerena da eskasena galdegaia aditzaren ondoretik ematen (salbu gaur eguneko estandarrean), eta aldiz altuena, bai galdegaia aditzaren aurretik ematen, eta bai bestelako esaldien artean, galdegaia aditzaren aurretik eta ondoretik banatua eman ohi duelako. Etxepare, nolanahi, mende honen hasieran ari da idazten bere Buruxkak, Hiriart-Urrutiren Eskualduna-ren itzaletik. Eta nik susmoa dut, egia da oraindik gehiegi aztertu gabea, seguru asko garai horretarako Azkueren hegada zabaldua dela jadaneko aipatu aldizkari eta zuzendariarengana, eta hauen bidez beren ingurura ere. Nolanahi, bestek ziurtatu beharko luke eragin hori, zeren Duvoisinen datuek ere apuntatzen dute, beste neurri batean bada ere, norabide horretara. 


\section{Ondorioz. Aditza esaldi aurrealde / atzealdean}

Hala kontsideratuko ditugu aditza esaldi aurrealdean, eta esaldiko pisu informatiboa haren atzealdetik, ematen duten esaldien artean, batetik, zuzenean aditzaz hasten diren esaldiak; eta bestetik, aditza tartean izaki ere, esaldiko pisu informatiboa nabarmen aditz honen ondoretik ematen dutenak; oro har, AzkueAltuberen galdegai legea beteko ez luketen esaldiak. Aldiz, kontsidera ditzakegu aditza esaldi atzealdean ematen duten esaldien artean, batetik, zuzenean aditzaz amaitzen diren esaldiak; eta bestetik, aditza tartean izaki ere, esaldiko pisu informatiboa nabarmen aditz honen aurretik ematen duten esaldi haiek; oro har, Azkue-Altuberen galdegai legea bai beteko luketenak. Hala, segidakoak lirateke gure emaitza, berriro, esanguratsuak:

Aditza esaldi aurrealde / atzealdean (eta esaldiko pisu informatiboa alderantziz):

\begin{tabular}{|l|c|c|}
\hline & $\begin{array}{c}\text { Aditza } \\
\text { esaldi } \\
\text { aurreald. }\end{array}$ & $\begin{array}{c}\text { Aditza } \\
\text { esaldi } \\
\text { atzeald. }\end{array}$ \\
\hline Axular & $\mathbf{5 6 , 0}$ & $\mathbf{4 4 , 0}$ \\
\hline Corpusa (batez beste) & 64,6 & 35,4 \\
\hline Idazleak (batez beste) & 72,0 & 28,0 \\
\hline J.A. Mogel & 85,3 & 14,7 \\
\hline J.B. Agirre & 93,0 & 7,0 \\
\hline J. Duvoisin & 57,2 & 42,8 \\
\hline J. Etxepare & 64,6 & 35,4 \\
\hline Webster & 75,3 & 24,7 \\
\hline Cerquand & 67,2 & 32,8 \\
\hline Euskalkiz euskalki & 56,1 & 43,9 \\
\hline Sara & 60,3 & 39,7 \\
\hline Zuberoa & 60,0 & 40,0 \\
\hline Baigorri & 80,2 & 19,8 \\
\hline Heleta & 69,2 & 37,1 \\
\hline Gaur egun & $\mathbf{1 8 , 2}$ & $\mathbf{8 1 , 8}$ \\
\hline
\end{tabular}

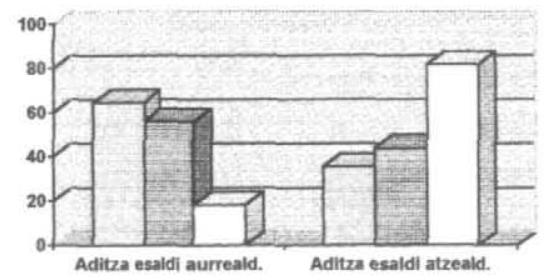




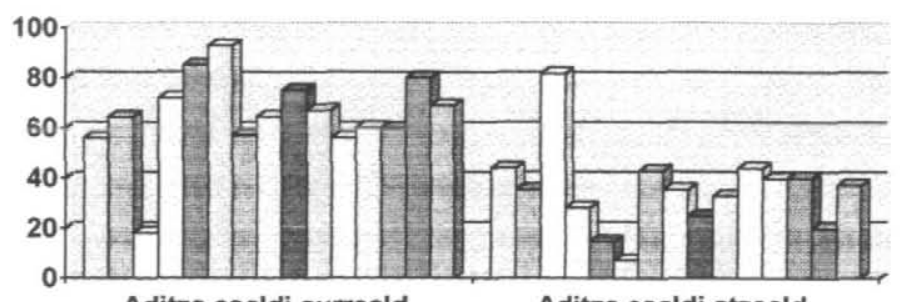

Aditza esaldi aurreald.

Aditza esaldi atzeald.

\begin{tabular}{|lll|}
\hline$\square$ Axular & QCorpusa & $\square$ Gaur egun \\
$\square$ Idazleal & $\square J$. A. Mogel & $\square$ J.B. Agirre \\
$\square J$. Duvoisin & $\square$ J. Etxepare & $\square$ Webster \\
$\square$ Cerquand & $\square$ Euskalkiz euskalki & $\square$ Sara \\
$\square$ Zuberoa & $\square$ Baigorri & $\square$ Heleta \\
\hline
\end{tabular}

Nabarmena da gaur eguneko prosa estandarraren desbideraketa, ahozko eta tradiziozko moldeetatik. Eta beharbada du horrek guztiak zerikusirik, guk hala uste dugu, gaur eguneko prosa estandarrak, oro har, eta oso bereziki itzulpenek eta testu didaktiko eta zientifikoek, erakusten duten ulergarritasun, zailtasun, nekosotasun eta komunikatibotasun arazoekin. Hori da gure hipotesia.

Nolanahi, nahikoa nabarmena da aztertu iparraldeko 3 idazleen joera aditz atzera zaleagoa hegoaldeko bien aldean. Nahiz gero ez den hala gertatzen Webster edo Cerquanden ipuin kontakizun bildumetan. Eta ez eta ere Euskalkiz euskalki-ko ahozko transkribapenetan, non iparraldeko lau testigantzak gertatzen diren batez bestekoak baino aditz aurrera zaleagoak, beraz hegoaldekoak baino nahikoa aurrera zaleagoak, eta batzuk gainera, Baigorrikoa kasu, oso nabarmen.

\section{Aditz gunea esaldian eta esaldien luzera}

Pentsatzekoa den bezala, esaldien luzerak, badu, besterik gabe ere, zerikusirik, aditza esaldi aurrealde edo atzealdean kokatze horretan. Hori suma genezake bederen konplementukako azterketa bat eginez. Soilik, Axularren eta corpus osoko esaldi nagusien joerak erakutsiko ditugu, kasu guztietan ere berdinak direlako joerak, are gaur eguneko euskara estandarrekoak ere:

Esaldi nagusiak konplementuka:

\begin{tabular}{|c|c|c|c|c|c|c|}
\hline \multirow[t]{2}{*}{ Axular: } & & & Ad. has. & \multirow{2}{*}{$\begin{array}{r}\text { Gald. ond. } \\
\% \%\end{array}$} & \multirow{2}{*}{$\begin{array}{r}\text { Gald. aur. } \\
\% \%\end{array}$} & \multirow{2}{*}{$\begin{array}{r}\text { Ad. amai. } \\
\%\end{array}$} \\
\hline & Kopur. & $\%$ & $\%$ & & & \\
\hline Konp. 1 & 10 & 6,2 & 10,0 & $1 / I I I I I I I I I I$ & $1 / I I I I I I I I I$ & 90,0 \\
\hline 2 konp. & 14 & 8,6 & 0,0 & 7,1 & 0,0 & 92,9 \\
\hline 3 konp. & 16 & 9,9 & 6,2 & 12,5 & 12,5 & 68,7 \\
\hline 4 konp. & 11 & 6,8 & 0,0 & 54,5 & 0,0 & 45,5 \\
\hline 5 (edo geh.) konp. & 111 & 68,5 & 9,0 & 61,3 & 1,8 & 27,9 \\
\hline Denera: & 162 & $100 \%$ & 7,4 & 47,5 & 2,5 & 42,6 \\
\hline
\end{tabular}




\begin{tabular}{|c|c|c|c|c|c|c|}
\hline Axular: & & & Ad. has. & Gald. ond. & Gald. aur. & Ad. amai. \\
\hline & Kopur. & $\%$ & $\%$ & $\%$ & $\%$ & $\%$ \\
\hline Konp. 1 & 422 & 10,2 & 26,8 & $1 / 1 / 1 / I I I I I I$ & $1 / 1 / 1 / 1 / 1 / 11$ & 73,2 \\
\hline 2 konp. & 597 & 14,1 & 15,6 & 22,9 & 8,0 & 53,4 \\
\hline 3 konp. & 583 & 13,8 & 11,8 & 38,1 & 10,1 & 40,0 \\
\hline 4 konp. & 467 & 11,1 & 11,6 & 49,3 & 10,1 & 29,1 \\
\hline 5 (edo geh.) konp. & 2,156 & 51,0 & 14,4 & 67,5 & 5,8 & 12,3 \\
\hline Denera: & 4,225 & $100 \%$ & 15,1 & 48,4 & 6,6 & 29,9 \\
\hline
\end{tabular}

\section{Axular}

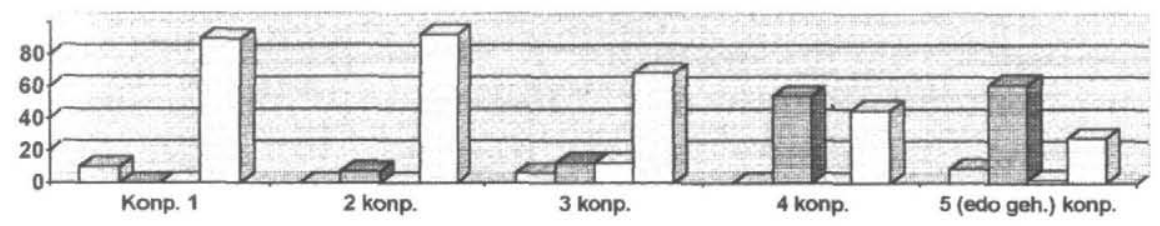

$\square$ Ad. has. GGald. ond. $\square$ Gald. aur. $\square$ Ad. amai.

\section{Corpusa}

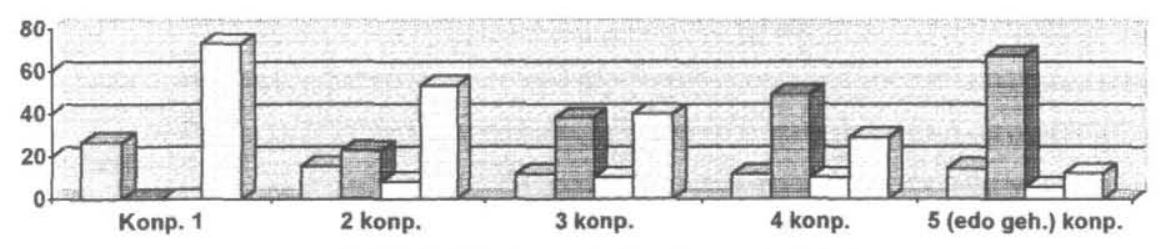

GAd. has. घGald. ond. $\square$ Gald. aur. DAd. amai.

Joerak bere batzuk dira.

\section{Mendeko esaldi jokatuak}

Axular, esaldi nagusien kasuan bezala, hainbat aditz atzera zaleagoa izango da, beste idazleen edo ahozko erabileren aldean. Urrun hala ere artean, esaldia aditzaz amaitzeko preskripzio Azkue-Altubetarretatik, edota gaur eguneko prosa estandarraren eredutik. Eta kasuan ez da joera homogeneo aipagarririk kausitzen iparraldeko idazleen artean. Hala datuak: 
Mendeko esaldietako aditz jokatua:

\begin{tabular}{|l|c|c|}
\hline & $\begin{array}{c}\text { Ad. esal. } \\
\text { amaieran }\end{array}$ & $\begin{array}{c}\text { Esaldi } \\
\text { hautsiak }\end{array}$ \\
\hline Axular & $\mathbf{5 6 , 1}$ & $\mathbf{4 3 , 9}$ \\
\hline Corpusa (batez beste) & 46,7 & 53,3 \\
\hline Idazleak (batez beste) & 41,0 & 59,0 \\
\hline J.A. Mogel & 39,5 & 60,5 \\
\hline J.B. Agirre & 25,5 & 74,5 \\
\hline J. Duvoisin & 49,3 & 50,7 \\
\hline J. Etxepare & 32,5 & 67,5 \\
\hline Webster & 60,4 & 39,6 \\
\hline Cerquand & 40,7 & 59,3 \\
\hline Euskalkiz euskalki & 49,4 & 50,6 \\
\hline Sara & 57,9 & 42,1 \\
\hline Zuberoa & 42,9 & 57,1 \\
\hline Baigorri & 38,3 & 61,7 \\
\hline Heleta & 43,7 & 56,2 \\
\hline Gaur egun & $\mathbf{7 8 , 0}$ & $\mathbf{2 2 , 0}$ \\
\hline
\end{tabular}

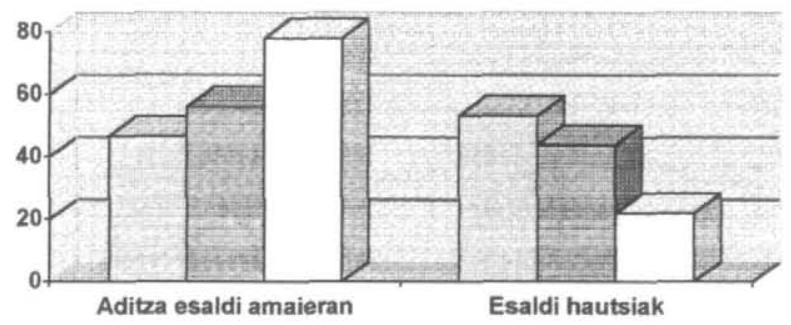

GCorpusa QAxular QGaur egun

Esaldien luzerak, kasuan ere, zerikusi handia du aditzaren gunearekin esaldi amaieran edo tartean. Zenbat eta esaldi laburragoak, orduan eta maizago aditza esaldi amaieran. Zenbat eta esaldi luzeagoak, orduan eta maizago aditza esaldi barrenean, konplementuak aditzaren bi aldeetara erakutsiz.

Aditz jokatugabe bidezko mendeko esaldiak

Autore eta hiztun guztietan ageri da, halako esaldietan, joera nabarmenagoa aurrekoetan baino, aditza esaldi amaieran emateko. Axularrengan inorengan baino areago ere bai, nahiz artean ez gaur eguneko prosan bezainbestekoa. 
Mendeko esaldietako aditz jokatu gabea:

\begin{tabular}{|l|c|c|}
\hline & $\begin{array}{c}\text { Ad. esal. } \\
\text { amaieran }\end{array}$ & $\begin{array}{c}\text { Esaldi } \\
\text { hautsiak }\end{array}$ \\
\hline Axular & $\mathbf{9 3 , 5}$ & $\mathbf{6 , 5}$ \\
\hline Corpusa (batez beste) & 78,7 & 21,3 \\
\hline Idazleak (batez beste) & 81,2 & 18,8 \\
\hline J.A. Mogel & 71,3 & 28,7 \\
\hline J.B. Agirre & 73,5 & 26,5 \\
\hline J. Duvoisin & 87,6 & 12,4 \\
\hline J. Etxepare & 82,0 & 18,0 \\
\hline Webster & 79,2 & 20,8 \\
\hline Cerquand & 74,4 & 25,6 \\
\hline Euskalkiz euskalki & 76,0 & 24,0 \\
\hline Sara & 69,2 & 30,8 \\
\hline Zuberoa & 66,7 & 33,3 \\
\hline Baigorri & 58,3 & 41,7 \\
\hline Heleta & 90,9 & 9,1 \\
\hline Gaur egun & $\mathbf{9 6 , 8}$ & $\mathbf{3 , 2}$ \\
\hline
\end{tabular}

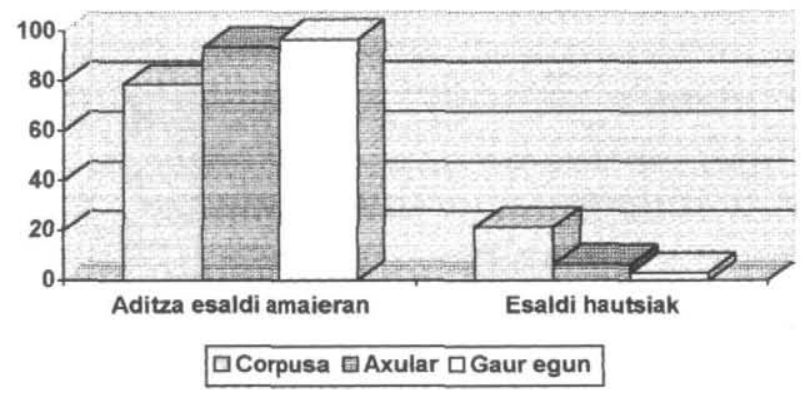

Beti bezala, esaldien luzerak zerikusi zuzena erakutsiko du aditzaren gunearekin esaldian. Zenbat eta esaldia laburrago, orduan eta maizago aditza esaldi amaieran. Zenbat eta esaldia luzeago, orduan eta maizago aditza esaldi barrenean.

$* * * * * * * * * * * * * * * * * * * *$

Bi ohartxo amaitzeko. Bata erlatibozko esaldi mota baten inguru. Bestea, Axularren esaldi buruko aditz trinko buruzurien gainean. 


\section{Erlatibo hautsiak}

Axularrena ez bada ere, Añibarroren esaldi batek azalduko digu puntua, azterketa merezi duelakoan. Hala dio Añibarrok Geroko gero-ari egin zion bizkaierazko itzulpenaren sarreran $(1923,299)$ :

Librucho au atera zan, ez bacarric Arimén oneraco, baita apaindu, aci, gorde-eraguin, edertu, ta zabaltzeco eusquerea; ta laguntzeco Euscaldun Icasle barriai; eta beragaitic ezteutsat quendu gura izan, Axularrec berac esqueñi, ta zuzendu eutsan Carta alabagarria Echaus Arzobispo Jaunari, eusquera garbi ederrean cirautsela onela: ENE JAUN BERTRAN DE ECHAUZ ...

Erlatibozko esaldi honetan, Echaus Arzobispo Jaunari datiboa, erlatibozko zuzendu eutsan aditzaren konplementu, lasai asko ageri da emana aditza eta honen gobernatzaile den izenburu nominal independente haren ondoretik. Kanon guztien kontrara. Ez dirudi, horregatik, ez dut nik bederen hala uste, ordenamendu horrek inolako eragozpenik dakarkionik esaldiaren ulergarritasunari, ezta ere, honen euskal jatortasunari. Ondoko guztiak ere zuzendu eutsan aditz horren osagarri izaten segiko luke.

Eta Axularrek ere badu antzekoren bat, oso oker ez banago, nahiz Añibarrorena bezain garbiak izan ez. Hala, esateko, segidakoa: ${ }^{10}$

Eta hunetacotçat, considera eçaçu, eriac gau lucean iragaiten duen trabaillua, guztiz ere eritasuna çorrotza, eta bortitza denean: nola irautcalcenden: nola orenak contatcen dituen: cein luce iduritcen çaitçan, eta nola arguia desiratcen duen. (598-9)

Bertan, guztiz ere eritasuna çorrotza, eta bortitza denean osagarria, iragaiten aditzaren denborazko konplementu litzateke. Antzeko beste esaldi bat izan liteke segidakoa, nahiz zerbait nahasiagoa:

Halaber eguiten baititutçu bertçe iuramentu batçuc, deus valio eztuten gauça batçuen gaiñean, ezpaita hequen hautzteaz calteric eta ez complitceaz probetchuric, nola baita, mahaian iartcean, etçarela lehenic iarrico, etchean sartcean, etçarela aitcinean sarthuco: edatean eztuçula lehenic edanen. (156-7)

non, ezpaita hequen hautzteaz calteric eta ez complitceaz probetchuric, esaldia litzatekeen valio izan aditzaren kausazko konplementu, hau da, zergatik delako gauza horiek ez duten deus balio-ren azalpena. Antzeko beste esaldi bat ere, nahiz hainbat nahasiagoa oraindik:

Eta çuc ere orduan, orai duçun desira, nahi baitcenduque, çure erremusinac, eta eguiten ditutçun bertce obra onac, munduac iaquin litçan, complituco duçu. (230)

Ez ote da, berriro, nahi baitcenduque, çure erremusinac, eta eguiten ditutçun bertze obra onac, munduac iaquin litçan esaldia duçun horren (orai duçun desi$r a$ horren) kausazko konplementu?

Behartu litezke halako interpretazioak kasu gehiagotan ere, segidako esaldietan bezala. Hala ere, oso eztabaidagarriak gertatzen dira interpretazio horiek, ez direlako a posteriori egin litezkeen interpretazio bakarrak, nahiz bai izan irakurketaren kadentzian eta sekuentziazioan ematen direnak. Hala: 
Içan çutenean Erroma-tarrec, desiratcen çuten abantailla eta garaitia Cartagotarren gaiñean, sarthu ciren conseilluan Erromatarrac, ea cer eguinen çuten, Cartagoco hiri hartçaz. (30)

Zeren osagarri da Cartagotarren gaiñean hori, bere hurbileneko desiratcen çuten aditzarena, ala hasierako içan çutenean harena? Zeinahi osagarri, lehen kolpean, lehen interpretazioan, emaniko hurbileneko aditzarekin lotuko du beti irakurleak beste eragozpenen ezean. ${ }^{11}$

Bada zuc iragan diren urthe guztiotan, behin ere ongui cofessatu gabe, beccatutan gogorturic eta ez ansiaturic çaudecinorrec, certan baratu uste duçu? (110)

Zeren osagarri da behin ere ongui cofessatu gabe hori, jada emaniko eta hurbileko iragan diren aditzarena, ala artean etorkizun den çaudecin horrena? Irakurlearen interpretazioak lehenengoarekin lot lezake esaldia lehen kolpean, eta hausnarketa ondoren beharbada bigarrenarekin.

Utçaçu beraz burutic, buruan darabillaçun erhoqueria hori, egunetic egunera, heriotceraiño luçatuz eta eppe hartuz, orduan erremediatuco çarelaco esperantçarequin, anarteraiño beccatutan egoite hori. (217)

Berriro, egunetic egunera, heriotceraiño luçatuz eta eppe hartuz eta orduan erremediatuco çarelaco esperantçarequin osagarriak ezin ote dira, lehen kolpean, besterik gabe onartu buruan darabillaçun esaldiaren konplementu bezala?

Badirudi, nolanahi, halako esaldi erlatibo hautsiak beti maizago aurkitzen ahal direla egitura erlatibo fosilduetan, h.d. ohiko erlatiboak diren haietan: - $n$ bezala, -n moduan, $-n$ arte (an; ...), $-n$ bitartean, ... itxurako egituretan. Hala, esateko, Axularren segidako $-n$ bezala esaldiotan:

Erraiten du San Agustinec, emazte gaixtoac, ithaiçurac, eta kheak atheratcen duten beçala giçona bere etchetik: atheratcen duela concientcia gaixtoac ere beccatorea bere sosegutic. (427-8)

Vespasiano Emperadoreac hain çuen condicione ona, eta onera emana, ecen nahi etçuen beçala, edo haren presunari etcegocan beçala nehor minçatcen ceicanean, edo disimulatcen çuen, edo cenbait hitz iocolariz eta dostailluz, cenbait irri eguiteco solhasez ederztatcen çuen, eta guero bere cegocan ohorearequin, deus galdu gabe, guelditcen cen. (313)

\section{Edota Axularren segidako - $n$ bitartean itxurakoak:}

Baiña iccussiric cein gauça guti edireiten den euscaraz esquiribaturic, gogan behartu naiz eta beldurtu, eztiren bideac asco segur eta garbi, baden bitartean cenbait trabu edo behaztopa-harri. $(16)^{12}$

Are errazago aurkituko ditugu, noski, halako egitura hautsiak erlatibo nominalizatu libreen artean, h.d. izenburu independente gabeetan. Oso maiz -nean denborazko egituretan (Axularren kasuan, halakoen \%15 - \%20aren inguruan gure azterketan), nola segidakoetan erakusgarri:

Ebaquitcen duçunean çuhaitz bat, eta berriz hartaric urt-umeac edo adarrac sortcen direnean, agueri da etcenduela ossoqui, eta ondotic ebaqui, guelditu cela cenbait erro eta zain. (465)

Ene seme hasten çarenean Iaincoaren cerbitçatcen, çaude erne, eta veldur çarela, eta presta çaite tentamenduey contra eguiteco. (477)

Presuna batec eguiten duenean beccatu mortal bat, bi gauça eguiteintu. (575) 
Eguiten denean penitencia, eztira Iaincoaren mehatchuak, mehatchu baizen. (617)

Baina ez ere soilik halakoetan, nola ikus litekeen segidako adibideen antzekoetatik:

Eguiten deracunari gaizqui, cergatic eguin behar diogu ongui? (322)

Ifernuan daudenec anhitz milla urthez, pena hetan egonez guero, iccussiric bere pena iraganez eztutela bat ere probetchuric: considera ahal diteque, ecen bere gogoetan tristeric, eta ilhunic, minçatuco çaitçala Iaincoari, eta erranen diotela: Cerda haur Iainco handia, non da çure misericordia, urricalmendua, eta pietatea? (606)

Galdera, nolanahi, konplexua litzateke: zein baldintzatan gerta ohi liteke euskaraz arrunta, edo bederen eramangarria, halako osagarriak eman ahal izatea inoiz erlatibozko aditzaren eta honi erantsitako buru nominal independentearen ondoretik? Erantzuna beste batean. ${ }^{13}$ Eta ez dut hemen besterik aipatuko Axularren erlatiboen inguru, nahiz balegokeen zer esanik.

\section{Axularren aditz trinkoak esaldi hasieran}

Amaitzeko, beste oharño bat baino ez, Axularren esaldi buruko aditz trinkoen inguru. Guk Axularri estatistikoki aztertutako zatian ez da halakorik ageri. Eta gure corpus osoan ere, ez dira halako 38 esaldi baino gertatzen, aztertu 4.488tik (guztien \%0,85a). Nahiz, esateko Mogelek besteek baino nahikoa gehiago erabiltzen dituen ( 20 esalditik lean gure corpusean). Hala ere, Axularrek berak baditu halakoak, nahiz egia den gutxi direla, eta dituenak, nahikoa markatuak. Hala segidan sail bat:

\section{- Esan aditza esaldi buruan buruzuri:}

- Ezta pontu hunetara gaizqui heldu Pierres Damiano daritçan doctor batec contatcen duena. Dio doctor hunec ecen behin guizon saindu batec iccussi çuela bere espirituan, ametsetan beçala, ifernuko suaren erdian escalera bat: eta escalera haren lehen pausuan, eta maillean cegoela Conde bat, iaun handi bat. (246)

- Esan aditza eta juntagailuaren ondoren:

- Utzten ditut placer haren aitcin-gibelac, anarteraiñoco, eta ondoreco eguitecoac, eta atsecabeac, handiac baitira, baiña hartan çareneco bereco placeraz mintço naiz: eta diot ecen orduan ere, hartan çarenean ere, cerbait escastasun, cerbait descontentamendu içaiten duçula; eta hura dela causa, orduan ere, guztiac ongui contatcera, placer baiño desplacer gehiago içaiten duçula. (383)

- Eta diot ecen, are mundu hunetan ere, guiristino onec, Iaincoaren partea daducatenec, atsegin eta placer gehiago goçatzen dutela, guiristino gaixto Deabruaren partea seguitcen dutenec baiño. (505)

- Izan aditza eta juntagailuaren ondoren:

- Pontu hunetara ezta gaizqui heldu, San Matheo Ebangelistac ibentcen duen comparacino bat, ceiñetçaz frogatcen baita, beccatuetan beçala, obra onetan ere, neurria betha arteiño, eta çorhi arteiño, iguriquitcen duela Iaincoac. Eta da comparacinoa: Guizon batec erein çuen bere landan haci ona, ogui bihi garbia. (11920)

- Hartaracotzat edireiten da bertcebat San Geronimo baithan, eta ene ustez ez gaixtoa. Eta da arrazoiña: Prometatu cerauen, iguriquico cerauela ehun eta hogoy urthez, ez ordea iguriqui ehunez baizen. (123) 
- Baiña eguiteco hunetan sarthu baiño lehen, nahi nuque iaquin ceneçan gauçabat, eta da: Nola eguiazco penitencia baita Iaincoaren donua, dohaiña, eta emaitça, Iaincoac berac placer duenean eman dezaqueyena: hala eguiazco penitencia hura, noiz nahi den dela, heriotceco azquen orenean bada ere, salbatceco asco sendo eta botheretsu dela. (195)

- Halatan Apostoluec ere orduan cedutçaten bere buruac dohatsuenic, eta ciren aleguerenic noiz eta Iaincoagatic desohore eta laido guehiago errezibitcen baitçuten. $(487-8)$

- Ceren amorio garbiak, Iaincoaganic heldu denac, indar guehiago behar luque, eta du ere, Deabruaganic helduden amorio higüin, hats, lizunac baino. (489)

- Izan, egon, esan aditzak baina juntagailuaren ondoren:

- Ceren bataz placentcia hura ezta placentcia, baiña da enganamendu: eta enganamendu hura ere, ezta ez beccatuarena, eta ez beccatutic sortcen dena: baiña da beccatorearena, beccatorea beraganic, eta beccatuaren eraguille Deabruaganic heldu dena. (510)

- Hura ezliçateque misericordia, baina liçateque iustizia falta: eta Iaincoa baithan ecin dateque halaco faltaric. (614)

- Hec han bere beccatuez damu eta urriqui badute ere; eztute ez damu eta urriqui hura, behar beçalacoa; eztute Iaincoagatic, eta ez Iaincoari çor dioten amorioagatic, baiña dute iragaiten dituzten penacgatik. (616)

- Etsaitasuneco victoria, eta garaitia, eztago ez mendecatcean, eta ez ordaiñaren bihurtcean edo doblearen: baiña dago barccatcean, eta bidegabèn pacientqui pairatcean. (320)

- Eztu erraiten Iondone Pauloc, bertce beccatuez bezala, emaztètaco beccatuari defenda gaquitçala: eztu erraiten harmetan moccoz-mocco iargaquitçala, baiña dio, fugite, ihes daguigula. (398)

- Izan aditza ordea juntagailuaren ondoren:

- Ceren eguia da, gauza hauc guztioc penitenciac dira, eta penitenciazco obrac: ordea dira campocoac, eta eguin ahal ditezqueyenean cenbait bedere eguin behar direnac. (197)

- Izan, jakin aditzak othe partikularen ondoren:

- Otheda munduan bat ere halacoric? (142)

- Othe da nehor, elhorri-arantcétaric mahats, edo saphar-laharretaric fico viltcen duenic? (216)

- Othe lizateque nehor ere, hequen artean, bicitce lucearen esperantça luenic? (59)

- Othe dugu centçuric? Othe dugu adimenduric? (599)

- Othe ciaquien cer nahi cioen Iaincoac? (434)

- Izan, esan, egon, iruditu aditzak, koma baten (edo pausa baten) ondoren, zeina, noski, ez den kasu erabat berdina, baina bai oso antzekoa:

- Finean esquiribatce hunen gaiñean, diot ezen, nola latinac bi $i$ eta bi $v$ eguiten baititu bat, eta hartcen batentçat: adjicio, conjicio, vultus, vulnus. Eta Espaiñolac ere bi $l$ eguiten baititu bat, llamo, lloro: hala euscarac ere bi $t$ eguiten dituela bat, ttipia, ttipittoa, gizonttoa, haurttoa. (18)

- Onguiric ez eguitea, bera, da gaizqui eguitea. (39)

- Baiña calte guztien gaiñeko caltea, alferqueriatic heldu den handiena, ceiñi narraicola erran baitut nic, oraiñocoan erran dudan guztia, da luçamendua, gerotic gerora ibiltcea. (44)

- Orai Iaincoac emaiten derauzquitçun bizitcea, osasuna, indarra, antcea eta onhasunac nahiditutçu Iaincoaren beraren contra çabiltçala higatu eta galdu, eta guero, oraiño eman ezterauzquitçunac, eta venturaz emanen ere ezterauzquitçunac diozu ecen, haren cerbitçuan enplegatuco ditutçula. (66-7)

- Orai Iaincoarequin adisquide çarenean, beccaturic gabe çaudenean, eztuçu esperantçaric Iaincoac çuregatic deus daidiqueyela; çure premia estal 
deçaqueyela: eta guero etsai çarenean, eta beccatuz bethea çaudenean, duzu fidantcia, guztiac barccaturic, bere garacia eta loria, hain gauça handiac, valiosac, eta erdiesteco gaitzac, emanen derauzquitçula. (148)

- Ceren gu gabiltça munduan barrena sarthuac, aberatstasunez betheac, atseguinez, eta placerez gaiñez eguinac, eta çu penitenciatan, obra onetan, munduco eguitecoetaric campoan, eta guztiarequin ere diozu sinheste, eta esperantça guehiago dugula çuc baiño? (149-50)

- Eta calte principalenetaric bat; principalena ezpada ere, da adimenduaren goibeltcea, ilhuntcea, eta itsutcea. (341)

- Eta hala beccatu hunetaric beguiratcea, eztago ez guztia adinean, eta ez indarrean, baiña bethi ere Iaincoaren faborea aitcinean hartcen dela, dago gogoan, eta gogoaren deliberamenduan. (376)

- Barreneco aitzindari haur edo argui eguille haur, cein deitcen baitute doctorec Synderesis, da gure concientcia edo arraçoin naturala. (420)

- Galdeguin ceraucaten egunbatez Bias philosophoari ea othecenz munduan deus, deusen veldur etzenic? (448)

- Ceren concientcia ona duenac, du esperantça ere. (450)

- Eta nola Iesu Cristoc berac, baitceducan bere divinitatea, eta Iaincotasuna barrenean estalia, eta campoan baitcirudien ttipi, eta probe: hala haren cerbitçariec ere bere iaunari iarraiquitcen çaitçala, dirudite campoan deus guti, eta triste, baiña barrenean dira alegera eta consolamenduz betheac. (509)

- Verthuteac, Iaincoaren cerbitçatceac, prestuqui bicitceac, ondore ona du, eta cerbait trabaillu badu ere, du appurra eta laburra: eta labur hura ere arintcen, gutitcen eta goçatcen du, ondoreko irabaciaren eta placentciaren segurantzac; gogotic, amorioz eta borondatez egoiteac, eta guztien gaiñetic Iaincoaren laguntçac eta faboreac. $(521-2)$

- Legue naturalean asco cen bihotzezco urriquimendu batequin, eta bat bederari bere gogoac, bere baithan barrena, ziotsan campoco cenbait seiñalerequin, contu eguizu begui ailtchatce batequin, edo belhauricatce batequin, Iaincoari berari cofesatcea eta barccamendu escatcea. (523)

- Bada nola isatsaz maiz iragaiten den etchea, erraz baita garbitcen, ceren harc fitsmits, eta liquitsqueria guti baitu: baina urthean behin baicen garbitcen eztena, neque baita, eta gaitz, ceren harc herrautsa, eta amaraua lodi baitu: hala molde berean maiz cofesatcen dena erraz beçala, gutitan eguiten dena ere, da neque eta gaitz. (540-1)

- Eta haren erranaren eta iduriaren arauaz, diot ecen, eztela ifernuan içanen elhurric, hormaric eta ez bertce hotz suerteric. (584)

\section{Ondorio gisa}

Axularrek bada bi ezaugarri bederen erakusten ditu bere hitzen antolamenduan. Batetik, tradiziozko beste idazle guztiak bezalaxe, Axular ere ez zaie batere ongi lotzen Azkue-Altuberen preskripzio apokrifoei, salbu aditzaz amaitzen dituen esaldietan. Bestetik, nolanahi, uste dugu aitortu behar zaiola Axularri berezitasun bat hegoaldeko idazle gehiengoaren aldean, Axular, dena den, hauek baino nahikoa aditz atzera zaleagoa gertatzen delako, agian, hobeto aztertu beharreko iparraldeko tradizio zabalago baten harian. 


\section{Bibliografia aipatua}

AgIRRE, J.B. (1808) Eracusaldiac, Tolosa, 1850. Argitalpen faksimila, Hordago, Donostia, 1978 .

Altube, S. (1919) De sintaxis euskérica. Donostia, 1920.

_, (1929) Erderismos. Euskera, 1929; Euskaltzaindia, 1975 (A. Villasanteren hitzaurrea).

AÑIBARRo, P.A. (1800a) Gramática bascongada para el uso y alivio de párrocos y predicadores bizcaynos, guipuzcoanos y navarros. ASJU, 1969, III, 3-169 (sarrera , A. Villasante).

_, (1800b) Axular: Gueroco guero ... Bizcayco eusquerara ... RIEV, 1923, 1925, 1926, 1928, 1929, $1931,1933$.

Apaolaz A, A. (1890) Pachico Cherren. Bergara, 1890; Erein, 1992.

ARIZTIA, M. (1934) "Laburditar ipuñak”. Anuario de “Eusko-Folklore”, T. XIV, 93-129.

ARRUE, G. (1878) Baserritar jaquintsuaren echeco escola. D.J.J. Moguel, Marquiñaco apaizac vizcai-eusqueran atera eta ... Guipuzcoacora itzulia. Tolosa, 1878.

_, (1948) J.A. Moguel: Peru Abarca. F. Arocena, "La versión guipuzcoana del Peru Abarca de Moguel", BSVAP, 1948, IV, 165-194 , 337-353.

ARXU, J.B. (1852) Uskara eta Frantzes Gramatika, Baiona, 1852; 2. arg., Baiona, 1853; 3. arg. Bi mihiren gramatika, uskara eta francesa, Baiona, 1868; Hordago, 1979.

AXUlar, P. (1643) Guero. Bi partetan partitua eta berecia. Bordele, 1643. Edizio faksimila, Euskaltzaindia, 1988. (Gero. Jakin, Aranzaz u, 1976, L. Villasanteren argitalpena).

_, (1800) AÑibarro, P.A. Axular: Gueroco guero ... Bizcayco eusquerara ... RIEV, 1923, 1925, 1926, 1928, 1929, 1931, 1933.

, (1909) Geroko-Gero. Kapitulu batzuk baino ez, in Euskal-Esnalea, 1909, 115-22; 134$42 ; 160-5 ; 183-90$. (P.A. Orkaiztegiren sarrera).

_, (1998) SAlABERRI, P. Axularren historiak. Pamiela, 1998.

AZKUE, R.M. (1891) Euskal-Izkindea. Gramática Eúskara. Bilbao, 1891.

_, (1894) Ensayo Práctico. (1896ko, Método Práctico-aren aurreko eskuizkribu argitaragabea, Euskaltzaindiako, Azkue bibliotekan).

_, (1896) Método Práctico para aprender el euskera bizkaino y gipuzkoano. Bilbao, 1896.

_, (1928) Discurso leido ante la Real Academia Española. Bilbao, Editorial Vasca, 1928. Madrid, 1989.

_, (1935-47) Euskalerriaren Yakintza. Madrid, Espasa-Calpe, 1935-1947 (4 tomo);

_, (1949) Estudio comparativo entre el vascuence y varias lenguas cultas. Bilbao, 1949 (El vascuence y varias lenguas cultas. Estudio comparativo. Bilbao, 1949).

Barandiaran, J.M. (1921-...) Eusko- Folklore. In Obras Completas, t. II, eta t. III. (zatiak, El Mundo en la mente Popular Vasca, III, Auñamendi, 27, 1962.)

Cerquand, J.F. (1874-1885) "Légendes et récits populaires du Pays Basque". Bulletin de la Société des Sciences, Lettres et Arts de Pau, 1874-5, 1875-6, 1876-7, 1884-5. Orain euskaraz soilik, Ipar Euskal herriko legenda eta ipuinak, Txertoa, Donostia, 1985-6, 2 tomo (A. Aranaren hitzaurrea).

Charencey, Comte de, (1975) Drouin, J-C. "Le comte de Charencey (1832-1916) et la langue basque". Bulletin de la Société des Sciences, Lettres et Arts de Bayonne, 1975, 309-315. 
Darrigol, (1827) Dissertation critique et apologétique sur la langue basque. Baiona, 1827.

Dartayet, J.P. (DARTHAYET) (1861) Guide ou manuel de la conversation et du style épistolaire français-basque. Bayonne-Biarritz, 1861 (2. arg. zuzendu eta gehitua, Baiona, 1876).

_, (1867) Le mécanisme de la construction du verbe basque en dialecte du Labourd et des pays limitrophes. Bayonne, 1867.

Duvoisin, J.P. (1858) Laborantzako liburua, EEE, Donostia, 1986.

Eli ZALDE, L. (1911) “Raza, lengua y nación vascas”. Euzkadi, VIII, 1911, 163-196, 243276, 323- 339.

Etxaniz, N. (1958) Euskal-Antzertiak. Kuliska Sorta 27-8, Itxaropena, Zarautz, 1958.

ETXEBARRIA, J.M. (1991) Zeberio haraneko euskararen azterketa etno-linguistikoa. Ibaizabal, Deustu, 1991.

EtXePARE, J. (1910) Buruxkak, EEE, Bilbo, 1992.

Gerriko, J.I. (1805) Cristau doctriña guzt iaren explicacioaren sayaquera. Tolosa, 1858, 2 tomo.

GĖze, L. (1873) Éléments de grammaire basque. Bayonne, 1875; Hordago, Donostia, 1979.

GREENBERG, J.H., (1963) "Some universals of grammar with particular reference to the order of meaningful elements". In: J.H. Greenberg (ed.), Universals of Language, 58-90, Cambridge (Mass), MIT Press. (2nd ed., 1966, 73-113;. ed. in italiano, in La tipolo gia linguistica, P. Ramat (ed.), 1 15-154).

HARRIET, M. (1741) Gramatica escuaraz eta francesez, conposatua francez hitzcuntza ikhasi nahi dutenen faboretan. Baiona, 1741.

Hidalgo, V. (1991) Altuberen irakurtzen. Altuberen azterketan. (Lan argitaragabea, doktoretza tesirako prestatua).

_, (1993) Hitzen ordena euskaraz. Euskal gramatikalarien testigantza: iritziak eta, praktika idatziak. (Lan argitaragabea, doktoretza tesirako prestatua). prestatua)

_, (1994a) Hitz ordenaren estatistikak euskaraz. (Lan argitaragabea, doktoretza tesirako

_, (1994b) "Euskal joskeraren mito kaltegarriak (I). Nola idatzi euskaraz modu arin, ulergarri eta aberats batean." Hizpide, 35, 1996, 39-51.

_, (1994c) "Euskararen hitz ordena librea. Euskal joskeraren mito kaltegarriak (II)" Hizpide, 36, 1996, 21-27.

, (1994d) "Aditza maiz euskaraz esaldi hasieran. Euskal joskeraren mito kaltegarriak (II I)” Hizpide 37, 1996, 23-31. SVO?". (1995) "Ohar estatistiko garrantzitsuak euskararen hitz ordenaren inguru. Euskara,

_, (1996) "Hurbiltze bat euskal hitz ordenaren tradizioari". FLV, 7 1, 1996, 21-43.

_, J. GarZIA (1997) “Hidalgo vs Altube”. El Correo, Territorios , 10, 1997-XI-5. Urtarrila, 19 $18-9$.

_, J. GARZIA (1998) “Ikastea pentsatzen euskaraz”. In Administrazio euskaraz, 19, 1998 _, (1998) "Baina, zer da euskal joskera?". In Administrazioa euskaraz, 21, 1998ko uztaila, _, (1999) Izenaren eskuin hedatzen diren erlatiboak euskaraz. (Eskuizkribua) 
INTXAUSPE, E.T. (1856) "Notes grammaticales". Gehigarria, Sen Mathiuren Ebanjelioa-ri, I-XLVI. Euskaltzaindiak berrargitaratu a $1991 \mathrm{n} . . .$, Bonaparteren lan guztien artean.

_, (1858) Le verbe basque. Bayonne, 1858; Hor dago, Donostia, 1979.

ITHURRI, J. (1895-....) Grammaire basque. Dialecte labourdin. Bayonne, 1895; H ordago, 1979.

KanPion, A. (1884) Gramática de los cuatro dialectos de la lengua euskara. Tolosa, 1884; faksimila LGEV.

Kardaberaz, A. (1760) Tellechea Idigoras, J.I. "Larramendi y Cardaveraz. Censura y réplica inéditas sobre un libro de piedad”, ASJU, 1968, 5-31. I, 399-455.

(1762) Dotrina Cristiana edo Cristiñau Dotrinea. In Euskal lan guziak, LGEV, 1973/4,

Lardizabal, F.I. (1856) Gramatica vascongada. San Sebastián, 1856.

LÉCLUSE, F. (1826) Grammaire basque. ASJU , 1987, 813-916.

LekuONA, M. (1918) Métrica vasca. Vitoria, 1918 (Idaz-lan guztiak. 1. Aozko literatura, 1978, 131-157).

_, (1954) "Aitzin-solas”. In P. Axular, Gero, 1954, Itxaropena, Zarautz, IX-XXX IV.

Luchaire, A. (1879) Études sur les idiomes Pyrénéens. Paris, 1879.

Mahn, C.A.F. (1857) Denkmaeler der Baskischen Sprache. Berlin, 1857; Frantzesezko itzulpen hasiera, RIEV, 1922, 560-8.

MiCHEL, F.X. (1857) Le pays Basque, sa population, sa langue, ses mours, sa littérature et sa musique. Paris, 1857; Elkar, 1983 (P. Lafitteren sarreraz).

MitxelenA, L. (1953) Arnaut Oihenart. BAP, 1953, 445-463 (bereziki, 459-462 orr). (Orain in Mitxelenaren Euskal Idazlan Guztiak -MEIG-, V, 1988, 35-57).

_, (1961) "Euskal iztegigileak XVII-XVIIIgarren mendeetan (Villasanteren erantzunaz)". Euskera VI, 1961, 5-26.

, (1968) Plan base o proyecto general sobre unificación. Euskera - Batasuna. Euskera, XIII, 1968, 203-219 orr. bereziki, Joskera atala, 218-9 orr. (Orain MEIG bilduman.)

_, (1977) Euskal hizkera eta euskal neurkera. Euskera, XXII, 1977, 721-733 orr. bereziki, Ate osteko eraskin gisa atala, 729-33 orr. (Orain MEIG bilduman.)

_, (1978) Miscelánea filológica vasca I. FLV, 1978, 205-228 orr. bereziki, Relato y orden de palabras atala, 220-224 orr. (Orainago, in Palabras y textos, EHU, 1987, 363-385)

_, (1979) Miscelánea filológica vasca III. FLV, 1979, XI, 213-236 orr. bereziki, Arratsaldea zen alakoa atala, 226-230 orr. (Orainago, in Palabras y textos, EHU, 1987, 411433)

, (1981) "Galdegaia eta mintzagaia euskaraz". In Euskal linguistika eta literatura: Bide berriak. Univ. de Deusto, 1981, 57-81 orr. (Orain MEIG bilduman.)

Mogel J.A. (1783) Cristinaubaren jaquinvidia ... Ifinieban Bizcaico Eusqueran, A. A. Cardaberaz J esuitiac. Orain urteten dau eusquera apaindubaguan. Tolosa, 1783.

_, (1802) Peru Abarka , Durango 1881. Argital pen faksimila, 1981.

OlaetXeA, B. (1763) Dotrina Cristianea, Vitoria 1763. (2. arg. zuzendua, Bilbo, 1775).

OrKaizTEgI, P. (1903) “Itz joskera”. In: Ibaizabal, 1903, Zk.: 94, 95, 96, 97, 98, 99, 100. 
_., (1906) Observaciones para hablar y escribir tolerablemente en nuestro idioma euskaro. Tolosa 1906.

_.,(1909) "Geroko-Gero". Euskal-Esnalea, 19 09, 115-6.

PaGola, R.M. (1984) Euskalkiz euskalki. Euskara Zerbitzua, Eusko Jaurlaritza, 1984.

RuJ, R.P.G. de, (1969) "Is basque an S.O.V. language?". FLV, 3, 1969, 319-351.

TARTAs, J. (1666) Onsa hilceco bidia. Orthez, 1666; RIEV, I, II, III, $1907-9$ (J.B. Darricarrèreren estudioaz).

_. (1672) Arima penitentaren occupatione devotac. Edizio kritikoa Patxi Altunak paratua. Ed. Mensajero, 1996.

URGELL, B. (1985) Refranes y sentencias-eko hitz ordenaz, zenbait ohar. 1985, eskuizkribua.

UrRuzuno, P.M. (1988) Ipuinak. EEE, Donostia, 1988.

VILlASANTE, L. (1952) "Literatur euskera. Laphurrtarr klassikoaren gain eratua". BAP, 1952-1, 91-119; 1952-2, 259-298.

_, (1956) "Comunicación del P. Villasante sobre la réplica del Sr. Altube al Sr. Michelena acerca de sintaxis vasca. - Estudios de sintaxis vasca”. Euskera, 1956, 14-18. duma).

_, (1961) Anduaga, G. Aitonaren uzta. Itxaropena, Zarautz, 1961 (A. Villasanteren bil-

_, (1961) Nere izena zan Plorentxi Angeles Sorazuren bizitza. Itxaropena, Zarautz, 1961.

_., (1966) "Domingo Agirre Badiola, 1864-1920", sarrera, Garoa, 4. arg., 3-16. 89-93.

_, (1970) "Sintaxis". In Hacia la Lengua Literaria Común. EFA, Serie Eleizalde (2. arg.),

_, (1971) ““Gizona eta euskaltzaina” A. Villasanteren hitzaldia Altubez”. Euskera XVI, $1971,77-83$.

$\ldots$ (1974) "Altuberen testamentua oroitaraziz". Euskera 1974, 249-255.

_., (1974) "Euskara idatziaren joskera. Euskal idazle zaharren gaitzestea XX. mendean". $F L V, 1974,325-342$.

—, (1975) "Hitzaurre gisa”. In S. Altube, Erderismos, Euskaltzaindia (berrarg.), V-XII.

$\ldots$, (1976) Sintaxis de la oración compuesta. EFA. Serie Eleizalde (bereziki, "Orden entre la oración principal y la subordinada", eta "Orden de colocación entre las subordinadas de un mismo período" atalak, 58-60).

_., (1978) Estudios de sintaxis vasca. EFA, Eleizalde.

, (1979) Historia de la literatura vasca (2. arg.). Aranzazu. (Autore desberdinen azalpenetan barreiatutako iruzkinak, bereziki Azkue, Altube eta XX mende honetako hegoaldekoen artean).

, (1980) Sintaxis de la oración simple. EFA. Serie Eleizalde (bereziki, "Ordenación de los elementos en la frase vasca", 227-260).

_, (1981/82) "Las oraciones causales en Axular". FLV XIII, 1981; XIV, 1982.

_, (1982) "Sarrera”. In Lapeyre, Kredo edo sinhesten dut esplikatua, Euskaltzaindia (berrarg.), 5-27. 
_, (1985) "Euskal anaforikoak". In Symbolae Ludovico Mitxelena septuagenario oblatae II, 971-980, Vitoriaco Vasconum, 1985.

_. (1986) La oración causal en vasco. EFA, Eleizalde.

_, (1988) "Hitzaurrea”. In AzkuE, R.M. Latsibi, Labayru (berrarg.), IX-XIV.

$\ldots$, (1988) "Prosazko tradizio sendo bat osatu beharra". In Euskararen auziaz, EFA, Serie Eleizalde, 141-154.

$\longrightarrow$ (1989) Aita Ubillos-en "Christau doctriñ berri-ecarlea". Liburu honen berezitasun ba tzuez oharrak, Euskera, XXXIV, 1989, 517-531.

Villasante, L.; LASARTE, M.P. (1980) "Perpaus kausalak Lapeyre idazlea baitan". Euskera $1980,537-563$.

XAHO J.A.; ABBADIE, A.Th. d', ( 1836) Études grammaticales sur la langue euskarienne. Paris, 1836.

Webster, W. (1877/1993) Euskal ipuinak. I eta II, EEE, Donostia, 1993, 2 tomo.

ZAMARRIPA, P. (1918) "La idea capital en las frases vascas". In Ratos de Euskeralogia, La Gaceta del Norte, 2 de Noviembre de 1918. 


\section{Axular et l'étude diachronique de l'ordre des mots dans la phrase basque}

\section{Résumé}

La conférence porte sur ce que représente la figure d'Axular par rapport à l'ordre des mots dans la phrase basque, et ceci selon deux perspectives différentes. Tout d'abord on parle de l'utilisation que le $\mathrm{XIX}^{\mathrm{e}}$ et le $\mathrm{XX}^{\mathrm{e}}$ siècles ont faite de la figure d'Axular, surtout au sud du Pays et pour ce qui est des préférences que chaque époque affiche au sujet de l'ordre des mots dans la phrase basque. Ainsi, la première moitié du $\mathrm{XX}^{\mathrm{e}}$ siècle refuse-t-elle la syntaxe d'Axular, en la considérant latini sante et étrangère, soit à cause de l'utilisation libre qu'il fait des particules anaphoriques et subordonnantes antéposées à la proposition, soit à cause de l'ordre des mots dans la phrase - ce deuxième aspect étant plus développé dans cette conférence que le premier -. Selon ces critiques, Axular fait trop avancer la position du verbe dans ses phrases. A cet effet, il est tout de même curieux de constater que le $\mathrm{XIX}^{\mathrm{e}}$ siècle avait vanté justement tout le contraire chez Axular, en le considérant à plusieurs reprises, au même titre que Kardaberaz, comme le seul auteur à mettre le verbe à la dernière position de la phrase. Existant donc depuis longtemps, la polémique concernant la position du verbe dans la phrase ne fait que rebondir.

Dans la deuxième partie de la conférence, on essaie de fournir quelques données objectives, statistiques, qui permettent de mieux situer l'auteur dans la controverse. Pour ce faire, on passe son œuvre au peigne fin pour y analyser la position qu'occupent dans la phrase le sujet, le verbe et le complément d'objet et pour y découvrir quel en est l'ordre prédominant. $48 \%$ des propositions présentent l'ordre SVO, alors que $25,5 \%$ se construit suivant l'ordre SOV ; ce dernier ordre coïncide avec les données tirées d'autres auteurs classiques et des textes oraux des $\mathrm{XIX}^{e}$ et $\mathrm{XX}^{\mathrm{e}}$ siècles. Ils diffèrent tous des données fournies par le professeur De Rijk, tirées de textes écrits au $\mathrm{XX}^{\mathrm{e}}$ siècle conformément à d'autres règles grammaticales de référence, et qui présentent pour la plupart l'ordre SOV.

Par ailleurs, on étudie la figure d'Axular en même temps qu'un large corpus aussi bien écrit que parlé, par rapport aux dispositions actuelles concernant l'ordre des mots. Chez Axular, tout comme dans le corpus étudié, la plupart des propositions présentent le verbe au milieu. Mais 8 sur dix de ces propositions présentent l'information la plus importante de la phrase en position nettement postverbale, alors que seulement $4,3 \%$ la met en position pré-verbale. Axular ne respecte pas les conventions de la langue basque écrite standard d'aujourd'hui. De toute façon nous voulons souligner le fait que 39,4\% des phrases de cet auteur présentent le verbe en position finale, contre seulement $28,1 \%$ du corpus général et $18,6 \%$ chez des autres auteurs. Par contre, $6,1 \%$ de ses phrases commence par le verbe, alors que c'est le cas de $14,3 \%$ du corpus général et du $18,1 \%$ du corpus d'auteurs classiques. Aussi peut-on peut-être deviner dans nos statistiques une légère différenciation entre les auteurs du nord et du sud du Pays, la tendance à faire avancer le verbe dans la phrase étant chez ces derniers beaucoup plus accentuée. Quoi qu'il en soit, les données fournies par le basque parlé, d'un côté et de l'autre des Pyrénées, d'aujourd'hui et du siècle dernier, ne diffèrent guère, 
et on découvre même une légère tendance à faire avancer le verbe dans la phrase, plus facilement au nord qu'au sud.

Enfin, on présente d'autres données concernant l'ordre des éléments dans la phrase subordonnée, certains types de propositions relatives non normatives, ainsi que des propositions d'Axular qui commencent dès le verbe synthétique conjugué.

\section{Notes}

1. Lan hau burutu ahal izan da, besteak beste, Eusko Jaurlaritzaren laguntzari esker, Hezkuntza, Unibertsitate eta Ikerketa Sailak, 1998-99 ikasturterako ikertzaileak prestatzeko zabaldutako programako beka baten bidez.

2. Ik., esaterako, Aita Villasanteren 1956ko "Comunicación del P. Villasante sobre la réplica del Sr. Altube al Sr. Michelena acerca de sintaxis vasca”, Euskera aldizkarian argitaratua, nondik aurrera bihurtzen den Aita Villasante, agerian, fede berriko.

3. Corpus honen osaketa zehatzaz, eta azterketa parametroen inguruan, ik. Hidalgo, 1994a. Idazleei dagokienean, bakoitzari bibliografian aipatutako obraren zati bat izan da aztertua, eta obra aukeratua, besteak beste, jatorriz euskaraz sortutako lana izatearen baldintzapean.

4. Guk, Axularren kasuan aztertu ditugu XXXI-LV bitarteko kapituluak (1643, 339-569; 1976, 383699). Tartasena, 1666ko Onsa hilceco bidia osorik. Aipatu beste autoreei, berriz, bibliografian aipatu obra, edo obraren zati bat, aztertu zaie. Ikertu beste obrei dagokienez, bakoitzarekin ematen da erreferentzia ohar propio batean.

5. Ik. Apaolaza, 1890.

6. Ik. Ariztia, 1934.

7. Ik. Etxebarria, 1991.

8. 7 testu labur hauetako datuak jasotzen dira B. Urgell 1985ean.

9. Euskalkiz euskalki saileko datuak atereak dira, aztertzetik, R.M. Pagolak, 1984an argitaratzen duen Euskalkiz euskalki grabazio bilketak.

10. Axularren aipu guztiak jatorrizko ediziotik egiten dira (hobe esan, honen 1988ko argitalpen faksimiletik).

11. Beharbada hirugarren aukera bat ere kontsidera liteke, non Cartagotarren gaiñean sintagma izan litekeen zuzenean abantailla eta garaitia-ren konplementu.

12. Agian izan lezake esaldiak beste interpretaziorik, bitartean adberbio soiltzat emanaz, aditzari lotu gabea, baina ez zaigu iruditzen plausibleena.

13. Ikus liteke erlatiboen inguruan, oraindik zirriborroko lana baino izan ez bada ere, Hidalgo 1999.

14. Eta orduan ere balirateke, bederen, salbuespenak, zenbait kasutan, gutxitan egia esan, esaldiko beste elementuren bat tartekatzen delako galdegaia eta aditzaren artean, hemen bestela aipatu ez dugun egitura batean. 